given a cup of strong coffee 45 minutes after the quinine dose. His fields were taken a quarter of an hour later, at which time he stated that he was beginning to feel better; the resulting improvement in each field has been shown by dotting the area gained. The patient's time being limited, the experiment had to be brought to an end. The colour vision remained normal throughout. It was not possible to test his light sense in the time available.

Remarks.-The main interest of the case lies in the fact that the dose given is the lowest yet recorded as having provoked quinine amblyopia, with a record supported by a careful examination of the patient. The extent of the reduction of the fields is remarkable, but the patient maintained that it was much less than he had often experienced. He attributed this to the good state of health he was in at the time. Possibly the fact that he took the quinine in powder instead of, as he had previously often done, in a solution of the ammoniated drug, furnishes a more reasonable explanation. The writer was naturally handicapped by his anxiety not to overdo the effect produced.

Caffeine has been recommended in the treatment of quinine amblyopia. A doubt as to the advișability of using this drug as a remedy might arise from Schwabe's case of a woman of 33, who had suffered for years from quinine amblyopia, and whose fields were always rapidly contracted by the ingestion of strong tea or coffee. That case is a very difficult one to understand, and the observations now published appear to indicate that caffeine has justly earned a reputation in the treatment of quinine amblyopia.

The question arises as to whether the original trouble with his vision may not have been due to the quinine then taken, rather than to the influenza. It is quite clear from the records of other cases that a previous decided attack of quinine amblyopia may render a patient unduly sensitive to the action of the drug ever afterwards.

The large doses in which some experts in tropical disease are advocating nowadays that quinine should be administered, raise a situation which demands that all cases of quinine amblyopia should be published. It seems doubtful if they have realised the danger that threatens the patient from the ophthalmic side of the question.

\title{
THYROID THERAPY IN OPHTHALMIC PRACTICE BY
}

$$
\underset{\text { PONDON }}{\text { PERCY DUN, }}
$$

Two years ago I contributed to the Lancet a paper entitled "Some Aspects of the Ciliary Body in Health and Disease,"* detailing

* The Lancet, 1916, Vol. 1. 
experiences gained of thyroid therapy in ophthalmic practice. As supplementing that paper, at the request of our editor, the following remarks are submitted, partly based upon additional experience, partly in an attempt to justify drawing further attention to the subject. The dominanit factor, emphasizing this suggested treatment, is the natural inference that without blood above suspicion in its freedom from toxic influences, the eye cannot maintain its resistance against pathological reaction; that a tissue of such delicacy and vascularity as that of the ciliary body should exhibit a disproportionate responsiveness to a toxic blood supply, is, under the circumstances, natural. There are many causes of toxaemia in which this responsiveness is displayed; these causes vary in their manifestation and effects; some are more prone than others to excite a reactionary process, and among them two, at least, are accompanied by signs, in which hypothyroidism is distinctly marked, namely intestinal putrefaction, and septic foci, such as in pyorrhoea alveolaris. The sequence of hypothyroidism in such cases is easily explained. One of the functions of the thyroid is to "exercise a protective, anti-toxic and immunising action, defending the body, not only against toxic products of its own metabolism, but against invasion by disease-producing micro-organisms and injury by their products." As long as the protective influence is maintained, pathological reaction is held in abeyance; as soon as that protection fails, reactionary processes ensue. Thus hypothyroidism, its existence being demonstrated by general signs, is of manifest import in oph thalmic practice. The irido-cyclitis of pyorrhoeal origin is a symptom, not a disease sui generis, and the determining cause of its incidence is failure of the thyroid to control the toxaemia of which the sepsis is the source. What is true in this regard of pyorrhoea alveolaris is also true of the iridocyclitis, commonly described as "keratitis punctata." Here the intoxication is perhaps most generally due to intestinal putrefaction. The fact remains that "keratitis punctata" is associated with a notorious reputation for intractability to treatment; the attribution of the inflammatory signs to toxaemic influences is recognized, but the failure of the thyroid to control the toxaemia is apparently overlooked. Hence the custom is to treat this irido-cyclitis upon general lines, with what satisfaction can be derived from fervent hope that improvement may in time follow, and yet this form of irido-cyclitis is essentially a hypothyroid manifestation. In this there may be, also, an underlying cause apart from, or in addition to, the intestinal putrefaction, inasmuch as I have found in many instances a family history of tuberculosis in the patients.

"Keratitis punctata" being, then, a symptom of toxaemia, as such it also postulates thyroid insufficiency, and hypo-thyroidism

* The Thyroid Gland in Health and Disease. By Robert McGarrison, p. 21, 1917. 
calls for thyroid therapy, a treatment which has proved very beneficial in the cases in which I have used it.

Let it also be remembered that an ill-functioning thyroid determines the virulence of a toxaemia and its effects. In varying degree the toxaemia, uncontrolled by thyroid action, reacts upon and depresses the nutrition. Thus we find corneal ulcers lagging in their repair, others spreading with an infective margin, others again accompanied by hypopyon. Logically, it may be presumed that none of these conditions would prevail were the toxaemia modified by thyroid activity. Where that control has failed, it must follow that the micro-organism is enabled to exert the maximum of its powers, and especially amid tissues defenceless from perverted nutrition; the virulence displayed in certain cases of a pneumococcal infection of the cornea must belong to this category. Of these infections hypopyon is not an uncommon complication. In such cases the toxin, passing through Descemet's membrane into the anterior chamber, acts as an irritant; an exudation of polymorphonuclear cells is the result, and the incidence of the hypopyon is the reflex of the virulence of the infection. It is arguable whether a fully-functioning thyroid could not check the formation of a hypopyon in all cases of pathogenic invasion of the cornea. Collateral evidence lends support to this view, a view which also suggests that the thyroid factor may explain the variability in infectivity which the pneumococcus displays. In the paper, "Some Aspects of the Ciliary Body in Health and Disease," the belief is expressed that interstitial keratitis is more a hypothyroideal manifestation than a syphilitic one. Hypothyroidism dominates the cases: the small patients are generally abjectly miserable in appearance, thin, dejected, nervous, physically weak, without desire for food, in bad cases intensely photophobic, and only tolerant of themselves and others when left undisturbed, buried among the bed clothes. To treat such children with 606 , or otherwise anti-syphilitically, is heroism misplaced. When general nutrition is good, a disease-tainted tissue may be able to maintain a functional balance of health; but when diminished resistance becomes the prevailing factor, then is the way open for the pathological bias of that tissue to become manifest. Again, a determining influence in these cases is possibly a taint of tuberculous origin. Zimmerman and others have found in the cellular infiltration of the cornea signs suggestive of tubercle. Whatever the cause may be upon which the thyroid insufficiency depends, the symptoms associated therewith are the first demanding treatment; and so, acting on this principle, I have found cases of interstitial keratitis yield quickly and satisfactorily to thyroid therapy.

Hypothyroidism may next be referred to in a different connection in relation to ophthalmic practice. At the menopause it has been 
shown that the thyroid is always functionally deficient. "At this time symptoms of hypo-thyroidism are apt to appear in women who throughout their child-bearing period have been sub-thyroidic. The stimulus of pregnancy to thyroidal activity during this period had sufficed to mask the gland's defect, which had become apparent on its withdrawal". (McGarrison). Many such patients, I feel sure, come under the notice of the ophthalmic surgeon. They are represented by anomalous eye symptoms-anomalous because no ocular cause can be found to account for them-such as aching of the eyes, more or less headache, a feeling of fatigue in the eyes after a short period of reading and close work. The general signs, however, of hypo-thyroidism in such patients are usually not definite. On the other hand, complaint is made of persistent "rheumatic" pains in the limbs and other parts, a prevailing lack of energy, and a dulness of spirit. If any refractive defect be present, the ocular signs are not relieved by its correction, for underlying it is the hypo-thyroid state, unsuspected, but nevertheless active. The proof is furnished by the relief obtained from thyroid treatment. In the course of the treatment the patient enters upon a new phase of life, in which troublous symptoms, for a long time persistent, vanish. "I have never felt better in my life," said a patient of the kind the other day, as the result of thyroid administration. And other similar cases have obtained the same relief. This has been an experience gained partly by following a rule- "when in doubt, try thyroid"; and on many occasions appreciation of the benefit has been expressed by patients in consequence of the adoption of that precept.

Another aspect of this subject may now be briefly considered. It is worthy of note that among the signs of thyroid inadequacy is haemorrhage. The evidence upon this fact is well authenticated, as reference to standard authorities will show. Possibly this sign has some, if not a close, bearing upon haemorrhagic manifestations in the case of the eye. There is the common form of sub-conjunctival haemorrhage, usually attributed to gout, suddenly occurring in middle-aged' women. There is what may be regarded as its analogue, sub-retinal haemorrhage, similarly supervening. The causes of retinal haemorrhages include a large variety, but Leonard Williams was the first to point out that among them he had noted thyroid insufficiency. He relates the following case.* An ophthalmic surgeon sent him a patient showing a fairly extensive retinal haemorrhage, with the suggestion that the cause was probably renal. The examination, however, in pursuit of that hypothesis proved entirely negative. On the other hand, definite evidence of hypo-thyroidism, on further inquiry, was present. Williams was impressed by this discovery, and it has led him to make a

* American Medicine, April, 1914, p. 273. 
point of ascertaining from patients suspected of hypo-thyroidism, whether this detail of haemorrhage had become noticeable in their case. This observation lends some significance to the haemorrhages in which the eye is concerned. A recurring subconjunctival haemorrhage pointing to hypo-thyroidism, should be accepted as a warning sign of a condition demanding thyroid treatment, in order to avert the contingency of the retina becoming the seat of the extravasation. Possibly a greater or less tendency to haemorrhage, in such cases, is general. Arterial haemorrhages, for example, presuppose cerebral contingencies of a similar nature. Eales some years ago reported "a series of cases of recurrent haemorrhage in the retina and into the vitreous from the retinal vessels, associated with epistaxis in young males in whom constipation and high arterial tension were present." * The cause of the haemorrhage was attributed to the constipation. Lawford, however, in commenting upon these cases takes a different view. "These cases," he writes, "albeit rare, are now fairly well known, and although the association of symptoms noted by Eales has been repeatedly observed, it seems most probable that there are more factors than one concerned in the production of the ocular lesions, and that constipation in young people does not per se lead to extravasation of blood from the vessels." $\dagger$ In support of that considered belief, expressed twentyeight years ago, the fact remains that among the various signs of hypothyroidism, haemorrhage is one, and persistent constipation another.

A few concluding remarks suggest themselves upon this subject, not from a therapeutic, but from a psychological aspect. The tendency more or less prevails to regard advocates of thyroid treatment as persons who take pot-shots at disease with thyroid tablets, and who, when succeeding occasionally in scoring a bullseye, persuade themselves that a thyroid target is the only one at which to aim. In short, that they elevate their practice into a "hobby," which they are prone to pursue always and on any occasion. I am not prepared to say that there is nothing in this criticism; but no doubt it is exaggerated. Meanwhile, it implies that thyroid advocates view their cases through thyroid eyes, a vision which focusses a thyroid glass upon disease generally, a vision which is distinguished by a contracted field. But this is not a correct representation of the facts, either in respect to the much debated organ, or to those who have faith in the therapeutic value of its substance. It should be borne in mind that the literature of the subject has now assumed massive proportions, and is soundly based upon physiological inquiry and research. That literature has

* Birmingham Medical Review, 1880.

$\dagger$ On Ocular Lesions dependent upon Disorders of the Secretory and Excretory Organs. Norris and Oliver, Vol. IV, p. 684: 
shown that the thyroid is the outpost of the defensive organic army of healthy nutrition. As Hertoghe has stated, "All the great causes of pathological disturbance, tuberculosis, syphilis, alcoholism, paludism, chronic starvation, consanguinity, etc., aim their first blow at the thyroid."* The admission, therefore, is unavoidable that thyroid therapy cannot be regarded as a "fad," liable at any time to be cast aside as a discredited fashion. Every day additional knowledge is being gained of its beneficent reality, and no one in these' days can afford to neglect its teaching. Hertoghe's forecast, therefore that "the day is coming when we will interrogate the thyroid equation (hypo- or hyper-) in all our patients with the same fidelity that we inquire into their previous history, in respect to tuberculosis, syphilıs, and alcoholism," may come to be realized in practice. The old common saying " a man is as old as his arteries" is sadly, out of date. Its misconception lies in its recognition of effects rather than of causes. A truer axiom would be "a man is as old as his thyroid," for it is the thyroid, as the regulator of nutrition, which keeps an old man; with vigour of mind and body, young, by counteracting auto-intoxication-Metchnikoff's theory of the cause of old age. It is the thyroid, too, which prevents and controls the advent and progress of arterio-sclerosis. Oftentimes dulness of spirit and a disturbing melancholy, irrepressible by volitional effort, are of toxaemic, and not of psychological origin : in such cases by stimulating a tired thyroid, the buoyancy of life is restored, and the mist-clouds of despondency dispersed. Finally, if thyroid therapy fails to yield the miracles expected of it after due trial, that is proof that the gland is in no need of assistance.

\section{CURIOUS RESULT OF EXPLOSION INJURY TO EYE}

BY

W. A. Anderson, Capt. R.A.M.C.

Eye examination of Pte. B-, March 20, 1917.

Two and a half years ago, whilst in the north island of New Zealand, he lit in a fire a roll of paper which, unknown to him, contained a tin of detonators. These exploded, and he was knocked over and wounded in several places, and a very small fragment entered the right eye, as the result of which he states he was blind for several days afterwards.

$R$. eye. To the nasal side of cornea, in the horizontal plane, there is a small, dark spot ; ? point of entry of foreign body.

\footnotetext{
"American Medicine, April, 1914.
} 